\title{
A validated method to help area reduction in mine action with remote sensing data
}

\author{
Yann Yvinec \\ Renaissance, ASBL \\ Royal Military Academy \\ 30, Avenue de la Renaissance, B-1000 Brussels, Belgium \\ yvinec@elec.rma.ac.be
}

\begin{abstract}
We present here a method to use remote sensing and GIS to help the task of area reduction in mine action.

The goal is to synthesize all relevant information in thematic maps, called danger maps, that can be used as basis for area reduction. The information presented in the maps can be extracted from the remote sensing data, coming from the Mine Action Centre Mine Information System (MIS) or be added after discussion with experts.

The blind tests performed on mine-suspected areas in Croatia have shown that the method had a reduction rate of $26 \%$ and an error rate of $0.1 \%$.
\end{abstract}

\section{Introduction}

One of the activity in mine action is the general mine action assessment consisting in continually gathering, evaluating, analyzing and making available sufficient information to assist and update the strategic planning of a national mine action programme [5]. This is usually done by sending teams to collect the needed information.

Several ways to use airborne data to help this process have already been explored [7][6][4].

This article presents the approach and the first evaluation done in mine-suspected areas in Croatia of a method using remote sensing data to help determining where areas that are not mined are. The approach is presented is fig 1 . This work has been performed in the scope of the European project SMART [9][8] by TRASYS, Renaissance ASBL (RMA), ULB-IGEAT, DLR, ENST, Zeppelin, CROMAC, RST and IXL.

This method has the following characteristics:

- the priority is to help find areas that are not mined rather than areas that are mined

- there is no detection of individual mines, but detection of clues to the presence or absence of mines or minefields

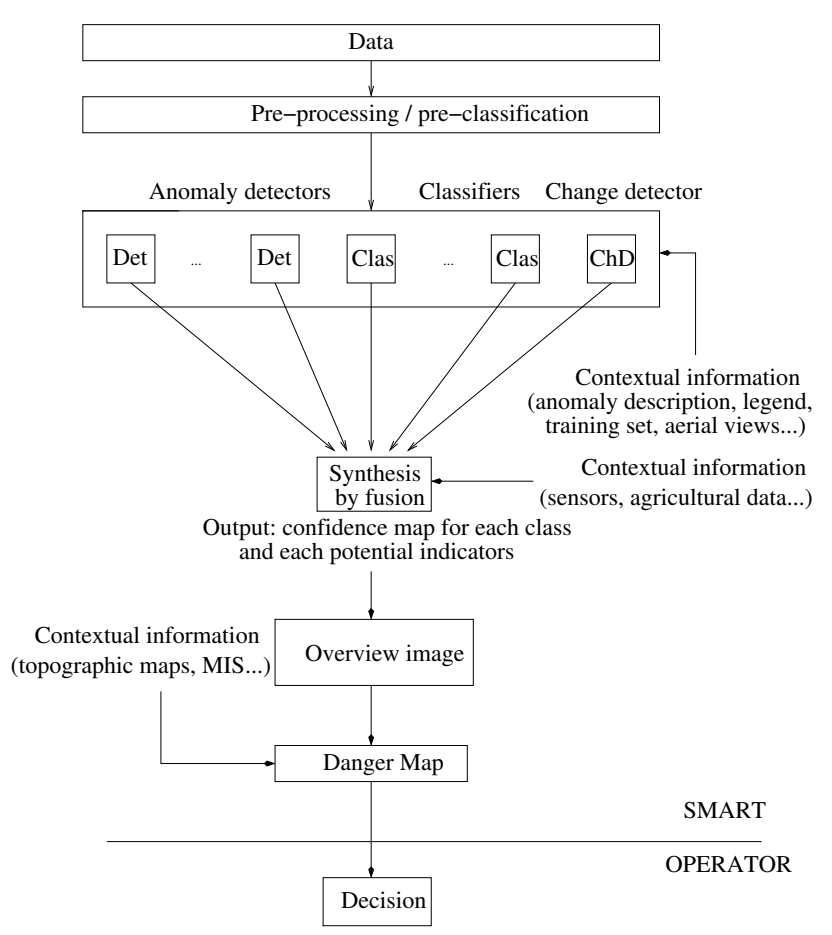

Figure 1. SMART functional description

- confidence maps are given in order to improve the interpretation of the danger maps

- results have been evaluated by blind tests

\section{Collecting the data}

We organised a flight campaign in Croatia in August 2001 to collect the airborne data. Data were collected on three mine-suspected test-sites in different regions: a fertile valley surrounded by hills (Glinska poljana), a very flat, 


\begin{tabular}{|l|l|}
\hline $\begin{array}{l}\text { Indicators of } \\
\text { mine absence }\end{array}$ & Indicators of mine presence \\
\hline $\begin{array}{l}\text { Cultivated } \\
\text { land }\end{array}$ & $\begin{array}{l}\text { Trenches and man-made embank- } \\
\text { ments }\end{array}$ \\
\hline $\begin{array}{l}\text { Asphalted } \\
\text { roads }\end{array}$ & Bunkers \\
\hline & $\begin{array}{l}\text { Infrastructural objects that are in } \\
\text { use }\end{array}$ \\
\hline & $\begin{array}{l}\text { Concealed paths to trenches or } \\
\text { bunkers }\end{array}$ \\
\hline & Shores of rivers \\
\hline & $\begin{array}{l}\text { River banks, shallow rivers or } \\
\text { creek, suitable for crossing }\end{array}$ \\
\hline & $\begin{array}{l}\text { Bridges (included destroyed } \\
\text { bridges) }\end{array}$ \\
\hline & Tracks that are no longer in use \\
\hline & $\begin{array}{l}\text { Agricultural areas that are no longer } \\
\text { in use }\end{array}$ \\
\hline & $\begin{array}{l}\text { Crossroads, especially crossings of } \\
\text { main roads with tracks no longer in } \\
\text { use }\end{array}$ \\
\hline & Irrigation/drainage channels \\
\hline & Edges of forests \\
\hline & Power supply poles \\
\hline & Soft edges of hardtop roads \\
\hline & $\begin{array}{l}\text { Tank and cannon holes (shelters for } \\
\text { tanks or heavy weapons) }\end{array}$ \\
\hline & Mine accidents and incidents \\
\hline & Minefield records \\
\hline & Confrontation zones \\
\hline & Hilltops and elevated plateaus \\
\hline & $\begin{array}{l}\text { Houses used by the military (rooms, } \\
\text { ammunitions stores, HQs, bunkers) }\end{array}$ \\
\hline & Damaged or destroyed houses \\
\hline & \\
\hline & \\
\hline &
\end{tabular}

Table 1. Indicators used in the test-sites in Croatia

agricultural area (Ceretinci) and a site near the coast (Pristeg). The data we used are Daedalus data (obtained from an optical scanner with 10 channels ranging roughly from blue light to thermal infrared with 1-meter resolution), E-SAR data (L-band and P-band full-polarimetric and dual-pass interferometric, C-band and X-band VV-polarisation, with a resolution from 2 to 4 meters), and RMK aerial photographs (3-centimetre resolution colour-infrared films). In addition we purchased satellite data from before the conflict, namely some KVR panchromatic images with a 2-meter resolution.

\section{Building a list of indicators}

After a field campaign we made a list of the features to look for in the data, based on what could be seen in the data and what could be related to the absence or presence of mines or minefields. If we want to help area reduction, that is, to be able to help stating that a mine-safe area is actually mine-safe, we have to focus on indicators of absence of mine infection. Unfortunately there are not so many of these indicators. In our three test-sites, the key indicator of mine absence seems to be the cultivated fields. Fields can indeed be cultivated in areas that the MIS of CROMAC, the Croatian mine action centre, labels as "suspect." See Table 1 for the list of indicators used.

Since most of the indicators in our list are indicators of mine presence, we realise that SMART has two uses: the area reduction as such - by detecting indicators of absence of mine infection -, and the reinforcement of suspicion - by detecting indicators of presence of mine infection.

It should be noted that these indicators are dedicated to Croatia. Many can be useful in other countries. But when working in another country, a careful analysis of the situation is necessary. For instance, if a cultivated land is a good indication in Croatia that there is no mine, in South Africa or Colombia it may be exactly the opposite because some farmers may mine their own fields to protect their crops.

\section{Extracting the information}

We use two ways to detect these indicators: anomaly detection and classification. Anomaly detection is the detection of specific elements in the data. Classification consists in assigning a land-use class to each pixel or region of the data. Satellite data from before the conflict was used to perform change detection and detect areas that were used before the conflict and have been abandoned since.

We integrate most of the tools and methods in a GIS environment compatible with the Information Management System for Mine Action (IMSMA).

\subsection{Anomaly detection}

In order to help the operator to extract the relevant indicators, detectors were defined. Many indicators are linear, so extractors of linear features adapted to SAR data and Daedalus multispectral data were built. Crossroads are found as intersections of roads. Likewise, intersections of roads and rivers help find bridges, even destroyed ones. A dedicated use of E-SAR data provided an extractor of aligned poles as described in [9]. Hilltops and elevated plateaus are detected by using a DTM.

\subsection{Classification}

Classifiers built specifically for this application include a minimum-distance discounted classifier, a classifier of multi-spectral data based on belief functions and SARspecific classifiers [3][2][1].

In addition to building some dedicated classifiers we have used commercial-off-the-shelf (COTS) software as complementary sources of analysis, such as a region-based 
classification. Besides automatic detection, interactive enhancement and extraction of anomalies - small artificial objects that are strong indicators of mine presence - were applied. For this purpose COTS software is used too.

\subsection{Change detection}

Since classification uses only current data it is not able to make the difference between a land that has been abandoned, for instance because of the presence of mines, and a land that is not used because it cannot be used for agriculture. Using satellite data from before the conflict, it is possible to see if a land that is not used now was already unused before the conflict or not. If it was the case then it is no longer possible to use the sole fact that it is unused to suspect a mine infection.

Edges of forests are indicators because forests can be used as a hiding place by armies. But since forest edges move over time we need to detect them at the time when the minefields might have been laid. Here again satellite data taken just before the conflict help.

\subsection{Data fusion}

A data fusion module is built to synthesize the classification results. First the results of various classifiers are fused at a low level. Then the knowledge is included: detection and interpretation of lines, SAR-specific classification of dedicated classes, such as rivers, results of change detection. Then a regularisation is performed by using a majority voting on regions extracted from the data.

Three methods are implemented for the low-level data fusion: two based on belief functions and one on fuzzy logic.

\section{Building a system to help a human decision}

A core element of the approach that we have chosen is to keep human beings at the centre of the whole process of area reduction. These operators will use the GIS environment, launch the tools, intervene at any step to complete, correct or discard results of tools, apply the methods and synthesize their results. The operators must therefore have a dual expertise: in mine actions and data analysis. So we have trained mine-scene interpreters to act as operators.

\section{The danger maps}

A great challenge is to define the best ways the operators will present their results to the decision makers performing the area reduction. For this purpose we have devised several continuous danger maps to provide a synthetic view of the information produced and of the confidence degrees attached to it.

These maps are the basis for proposing areas for area reduction. This method has been designed to be a preparatory stage that produces danger maps to help the area reduction. It is important to emphasize that the results are for decision makers and the reduction of a suspicious area is not an automatic process.

What is pictured in the danger maps is a weighted sum of factors derived from the mine-presence indicators, with a superimposition of vectors having a see-through inside, representing the mine-absence indicators. These maps provide the spatial distribution of the measure of danger, and are completed with 2 confidence maps, one for the minepresence indicators and one for the mine-absence indicators. This enables the human analysts to estimate the relative strengths of the information provided.

On the one hand, the decision makers can refer to information relating to the mine-absence indicators and the associated confidence values during the process of area reduction. On the other hand, the other key element is the information that concerns the mine-presence indicators and the associated confidence values. As pointed out by the end-users, this information can be of use for prioritizing the mine clearance operations.

\section{Results}

Validation was done by blind tests in three test-sites in Croatia: a fertile valley surrounded by hills (Glinska poljana), a very flat, agricultural area (Ceretinci) and a site near the coast (Pristeg). In each test-site clearing was performed after the flight campaign to have the true status of the mine presence. This information was of course not made available before the production of the danger maps.

From the danger maps, a first selection of areas to be proposed for area reduction was done, areas considered as suspect were selected too. For some areas the information available was not sufficient to make a determination: presence of water, forest, etc. Tables 2 through 5 show the correspondence between these areas and the mine infection.

The three test-sites cover an area of $3.9 \mathrm{~km}^{2}$. Glinska poljana: $0.63 \mathrm{~km}^{2}$, Ceretinci: $1.7 \mathrm{~km}^{2}$, Pristeg: $1.5 \mathrm{~km}^{2}$.

In average $26 \%$ of the mine-free area has been proposed for reduction (producer's accuracy). Glinska poljana: $7.7 \%$, Ceretinci: 47\%, Pristeg: $9.0 \%$.

Note that $0.10 \%\left(976 \mathrm{~m}^{2}\right)$ of what was proposed for reduction is actually mined (100 - user's accuracy). Glinska poljana: $0.058 \%\left(26 \mathrm{~m}^{2}\right)$, Ceretinci: $0.12 \%\left(924 \mathrm{~m}^{2}\right)$, Pristeg: $0.020 \%\left(26 \mathrm{~m}^{2}\right)$.

A ROC diagram can be built in order to compare the results. But for this we need a different definition of error rate. We choose therefore the following: the percentage of the mined area of the validation area that was (wrongly) included into the area proposed for reduction. The results are $1.1 \%$ for the three test-sites combined. Glinska poljana: $0.070 \%$, Ceretinci: $1.8 \%$, Pristeg: $0.70 \%$. The ROC diagram is given in fig 2 .

In addition to this technical evaluation a panel of independent mine action experts working in Croatia has evaluated the method and danger maps, and recognized their 
Table 2. Glinska poljana: first results of the tests in $\mathbf{~ k m}^{2}$ with user's accuracy (UA, or reliability accuracy, precision, predictive value) and producer's accuracy (PA, or reference accuracy, sensitivity, recall) in $\% .7 .7 \%$ of what was mine-free has been proposed for reduction. $\mathbf{0 . 0 5 8 \%}$ of what has been proposed for reduction was actually mined.

\begin{tabular}{|l|l|l|l|l|l|}
\hline $\begin{array}{l}\mathbf{G P} \\
\left.\mathbf{( k m}^{2}\right)\end{array}$ & $\begin{array}{l}\text { Considered } \\
\text { as suspect }\end{array}$ & $\begin{array}{l}\text { Proposed } \\
\text { for } \\
\text { reduction }\end{array}$ & $\begin{array}{l}\text { No } \\
\text { decision }\end{array}$ & Total & $\begin{array}{l}\text { PA } \\
(\mathbf{\%})\end{array}$ \\
\hline Mined & 0.037 & 0.000026 & 0.00010 & 0.040 & 99.7 \\
\hline $\begin{array}{l}\text { Not } \\
\text { mined }\end{array}$ & 0.51 & 0.045 & 0.038 & 0.59 & $\mathbf{7 . 7}$ \\
\hline Total & 0.54 & 0.045 & 0.039 & 0.63 & \\
\hline $\begin{array}{l}\text { UA } \\
(\%)\end{array}$ & 6.8 & $\mathbf{9 9 . 9 4 2}$ & & & \\
\hline
\end{tabular}

Table 3. Ceretinci: first results of the tests in $\mathbf{k m}^{2}$ with user's accuracy (UA, or reliability accuracy, precision, predictive value) and producer's accuracy (PA, or reference accuracy, sensitivity, recall) in $\%$. $47 \%$ of what was mine-free has been proposed for reduction. $0.12 \%$ of what has been proposed for reduction was actually mined.

\begin{tabular}{|l|l|l|l|l|l|}
\hline $\begin{array}{l}\text { Ce } \\
\left.\mathbf{( k m}^{2}\right)\end{array}$ & $\begin{array}{l}\text { Considered } \\
\text { as suspect }\end{array}$ & $\begin{array}{l}\text { Proposed } \\
\text { for } \\
\text { reduction }\end{array}$ & $\begin{array}{l}\text { No } \\
\text { decision }\end{array}$ & Total & $\begin{array}{l}\text { PA } \\
(\boldsymbol{\%})\end{array}$ \\
\hline Mined & 0.040 & 0.000924 & 0.014 & 0.053 & 99.7 \\
\hline $\begin{array}{l}\text { Not } \\
\text { mined }\end{array}$ & 0.68 & 0.80 & 0.22 & 1.7 & $\mathbf{4 7}$ \\
\hline Total & 0.72 & 0.80 & 0.24 & 1.8 & \\
\hline $\begin{array}{l}\text { UA } \\
(\%)\end{array}$ & 5.3 & $\mathbf{9 9 . 8 8}$ & & & \\
\hline
\end{tabular}

Table 4. Pristeg: first results of the tests in $\mathbf{k m}^{2}$ with user's accuracy (UA, or reliability accuracy, precision, predictive value) and producer's accuracy (PA, or reference accuracy, sensitivity, recall) in \%. $9.0 \%$ of what was mine-free has been proposed for reduction. $0.020 \%$ of what has been proposed for reduction was actually mined.

\begin{tabular}{|l|l|l|l|l|l|}
\hline $\begin{array}{l}\text { Pr } \\
\left.\mathbf{( k m}^{2}\right)\end{array}$ & $\begin{array}{l}\text { Considered } \\
\text { as suspect }\end{array}$ & $\begin{array}{l}\text { Proposed } \\
\text { for } \\
\text { reduction }\end{array}$ & $\begin{array}{l}\text { No } \\
\text { decision }\end{array}$ & Total & $\begin{array}{l}\text { PA } \\
(\mathbf{\%})\end{array}$ \\
\hline Mined & 0.0037 & 0.000026 & 0.0 & 0.0037 & 99.3 \\
\hline $\begin{array}{l}\text { Not } \\
\text { mined }\end{array}$ & 0.87 & 0.13 & 0.45 & 1.5 & $\mathbf{9 . 0}$ \\
\hline Total & 0.89 & 0.13 & 0.45 & 1.5 & \\
\hline $\begin{array}{l}\text { UA } \\
(\%)\end{array}$ & 0.4 & $\mathbf{9 9 . 9 8 0}$ & & & \\
\hline
\end{tabular}

Table 5. First results of the tests in $\mathbf{~ k m}^{2}$ with user's accuracy (UA, or reliability accuracy, precision, predictive value) and producer's accuracy (PA, or reference accuracy, sensitivity, recall) in $\% .26 \%$ of what was mine-free has been proposed for reduction. $0.10 \%$ of what has been proposed for reduction was actually mined.

\begin{tabular}{|l|l|l|l|l|l|}
\hline $\begin{array}{l}\text { All } \\
\text { three } \\
\text { sites } \\
\left(\mathbf{k m}^{2}\right)\end{array}$ & $\begin{array}{l}\text { Considered } \\
\text { as suspect }\end{array}$ & $\begin{array}{l}\text { Proposed } \\
\text { for } \\
\text { reduction }\end{array}$ & $\begin{array}{l}\text { No } \\
\text { decision }\end{array}$ & Total & $\begin{array}{l}\text { PA } \\
(\%)\end{array}$ \\
\hline Mined & 0.078 & 0.000976 & 0.014 & 0.093 & 84.0 \\
\hline $\begin{array}{l}\text { Not } \\
\text { mined }\end{array}$ & 2.1 & 0.97 & 0.71 & 3.8 & $\mathbf{2 6}$ \\
\hline Total & 2.2 & 0.97 & 0.73 & 3.9 & \\
\hline $\begin{array}{l}\text { UA } \\
(\%)\end{array}$ & 3.6 & $\mathbf{9 9 . 9 0}$ & & & \\
\hline
\end{tabular}




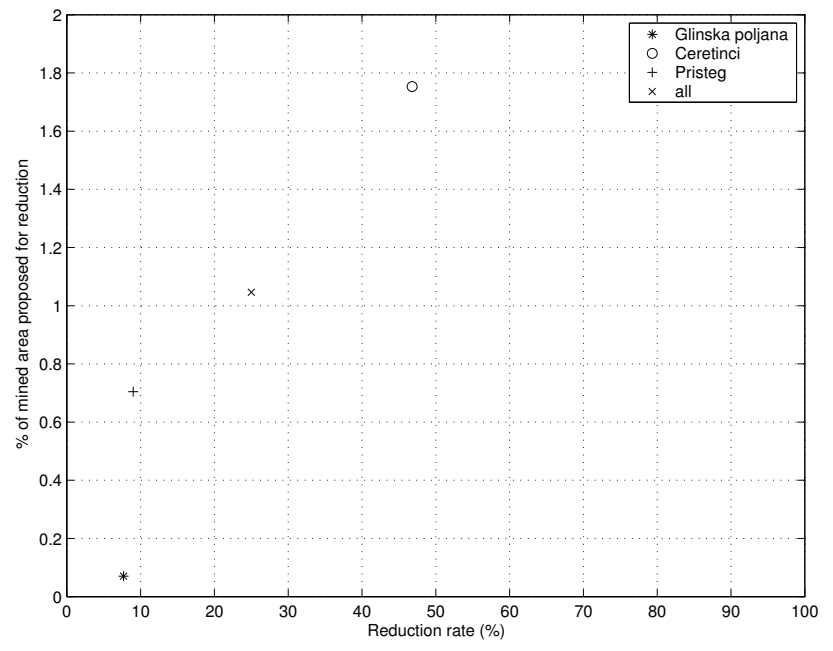

Figure 2. ROC diagram based on the results on three test-sites (for a better visibility the error-rate scale is from $0 \%$ to $2 \%$ )

contribution for an early stage of area reduction. It has been found that it might be even more suited for risk assessment.

In order to reduce an area one must be very confident that the area is risk-free. With few indicators of mine absence it may be difficult to reach the satisfying level of confidence. In this approach, however, the production of danger maps is useful in the first stages of area reduction. Later surveys will not have to spend time in spots where danger maps indicate that there are a lot of indicators of mine presence. But by focusing on areas where indicators of mine absence have been detected they can help reinforce the confidence that these areas should be reduced.

\section{Limitations}

It must be noted that three points have not been completely covered by the validation.

1. The cost-effectiveness analysis was performed but only partially, and more could be done to better assess the economic relevance of an airborne approach to area reduction.

2. The results are given only as raw figures, and a more detailed analysis on the results may be needed to see, for instance, where the $0.10 \%$ error that we obtain comes from, if it can be reduced or if it is inherent to the method, if we can foresee conditions where the SMART approach is more suitable and conditions where it may not be adequate, etc.

3. No analysis has been done yet regarding how the input can influence the results, for instance which sensors bring the more useful information, which tools extract the most relevant information, etc.
More could have been done in validation - a statement true in many research activities. But the validation done is sufficient to be confident that the proposed method can be useful to mine action centres.

\section{Conclusions}

We presented a method to help area reduction by the use of aerial and satellite data.

This method has been tested and evaluated. It involves the definition of indicators of mine absence and presence, their detection through land-use classification, dedicated detectors and change detection analysis, the combination of all these data with other available information - from the MIS, historical study, or visual interpretation of highresolution data - into danger maps that summarize the available information and its relevance.

The small number of indicators of mine absence makes it difficult to identify areas that could be safe, and even when such areas are found the small number of indicators may make the confidence low. However a panel of independent mine action experts working in Croatia has evaluated the project and recognized its contribution for an early stage of area reduction. One conclusion is that SMART might be even more suited for risk assessment.

A quantitative validation of SMART was performed on three test-sites in Croatia. SMART showed a significant rate of reduction of $26 \%$ (from $7.7 \%$ to $47 \%$ depending on the test-sites). But $0.10 \%$ of what was proposed for reduction was actually mined (from $0.020 \%$ to $0.12 \%$ ).

It must be noted that this method is not designed to provide the final stage of area reduction - which would require that $0 \%$ of the reduced area is mined -, but an early stage in the whole process. It provides danger maps, confidence maps of indicators of mine absence, and confidence maps of indicators of mine presence that help the interpretation of the areas proposed for area reduction.

Results can be improved by a better extraction of information from the remote sensing data and a better use of the danger maps and confidence maps in the selection of areas proposed for reduction.

\section{Acknowledgment}

This study was done in the project SMART co-funded by the European Commission (IST-2000-25044) involving the following partners: CROMAC, DLR, ENST, IXL, Renaissance ASBL (RMA), RST, TRASYS, ULB-IGEAT and Zeppelin.

This paper is largely based on SMART final report written by Milan Bajic (CROMAC), Isabelle Bloch (ENST), Bjoern Dietrich (DLR), Sabine Vanhuysse and Eléonore Wolff (ULB-IGEAT), Jacques Willekens (TRASYS), and Yann Yvinec (Renaissance/RMA). 


\section{Points of contact}

In addition to the author, points of contact for project SMART include:

Prof. Marc Acheroy

RMA - Royal Military Academy

Av de la Renaissance 30 , B-1000 Brussels, Belgium

Marc.Acheroy@rma.ac.be

Technical management

Prof. D. Sc., Milan Bajic

Scientific Council of CROMAC

Ulica grada Vukovara $226 \mathrm{c}$

10000 Zagreb Croatia

milan.bajic@zg.htnet.hr

Representative of the end-users and in charge of validation

Prof. Isabelle Bloch

Ecole Nationale Supérieure des Télécommunications

46 rue Barrault, F-75634 Paris Cedex 13

Isabelle.Bloch@enst.fr

Data fusion

Dr. Dirk Borghys SAR processing

RMA - Royal Military Academy

Av de la Renaissance 30 , B-1000 Brussels, Belgium

Dirk.Borghys@elec.rma.ac.be

SAR processing

Dr. Helmut Süß

DLR - German Aerospace Centre,

Oberpfaffenhofen, Germany

Helmut.Suess@dlr.de

Data collection, pre-processing and SAR processing

\section{Ir. Jacques Willekens}

\section{TRASYS SPACE}

Avenue Ariane, 7, B-1200 Brussels, Belgium

Jacques.Willekens@trasys.be

Project management and integration

Prof. Eléonore Wolff

ULB-IGEAT

CP246, boulevard du Triomphe, 1050 Brussels

ewolff@ulb.ac.be

Field surveys, classification, change detection and danger maps

\section{References}

[1] D. Borghys and C. Perneel. Combining multi-variate statistics and dempster-shafer theory for edge detection in multichannel sar images. In IbPRIA 2003, Lecture Notes on computer science, vol. LNCS 2652, pages 97-107, June 2003.

[2] D. Borghys, C. Perneel, M. Keller, A. Pizurica, and W. Philips. Supervised feature-based classification of multichannel sar images using logistic regression. In European Conference on Synthetic Aperture Radar (EUSAR), Ulm, Germany, May 2004.

[3] D. Borghys, Y. Yvinec, C. Perneel, A. Pizurica, and W. Philips. Hierarchical supervised classification of multichannel sar images. In 3rd Int. Workshop on Pat. Recog. in Remote Sensing (PRRS'04), Kingston-upon-Thames, United Kingdom, Aug. 2004.
[4] M. Eisl and M. Khalili. Arc - airborne minefield area reduction. In EUDEM2-SCOT-2003 Conference, pages 603-609, Sept. 2003.

[5] GICHD. Imas 08.10 general mine action assessment (edition 2). In http://www.mineactionstandards.org/imas.htm.

[6] Mineseeker. Summary report. In http://www.mineseeker.com/, Jan. 2001.

[7] J. van Genderen and B. Maathuis. Airborne minefield detection : pilot project, final report. vol. 1 and 2. 2000.

[8] Y. Yvinec. European project of remote detection: Smart in a nutshell. In Proc. of Robotics and Mechanical assistance in Humanitarian Demining and Similar risky interventions, Brussels, Belgium, June 2004.

[9] Y. Yvinec, D. Borghys, M. Acheroy, H. Sß, M. Keller, M. Bajic, E. Wolff, S. Vanhuysse, I. Bloch, Y. Y., and O. Damanet. Smart: Space and airborne mined area reduction tools - presentation. In EUDEM2-SCOT-2003 International Conference on Requirements and Technologies for the Detection, Removal and Neutralization of Landmines and UXO, Brussels, Belgium, Sept. 2003. 